\title{
Pseudomalignant myositis ossificans in the breast: A case report
}

\author{
KAMIL POHLODEK ${ }^{1}$, MIROSLAV JANÍK $^{2}$, IVETA MEČIAROVÁ ${ }^{3}$ and FRANTIŠEK ONDRIAŠ ${ }^{3}$ \\ ${ }^{1}$ Second Department of Gynecology and Obstetrics, Comenius University of Bratislava, Faculty \\ of Medicine; ${ }^{2}$ Department of Thoracic Surgery, Slovak Medical University of Bratislava, \\ 82606 Bratislava; ${ }^{3}$ Alpha Medical Pathology, Ltd., 84101 Bratislava, Slovakia
}

Received November 21, 2017; Accepted March 22, 2018

DOI: $10.3892 /$ mco.2018.1609

\begin{abstract}
Myositis ossificans (MO) is characterized by abnormal heterotopic ossification formation, typically involving muscles, tendons, ligaments, fascia, and aponeurosis. It can be categorized into nonhereditary and hereditary types, with the latter being a distinct entity with a separate pathophysiology and treatment approach. The pathophysiology of MO formation remains to be fully elucidated. MO is most commonly observed in muscle tissue as a solitary lesion. The disease has been reported to occur in all ages, including the very young and in atypical locations, including hands, feet, ribs, head and neck. The present case report describes an unusual pseudomalignant form of MO in the breast. The authors discuss the clinical and morphological characteristics of the tumor and its treatment options.
\end{abstract}

\section{Introduction}

Myositis ossificans (MO) is a benign condition characterized by abnormal heterotopic bone formation, typically involving striated muscle and soft tissue (1). In 1924, Noble (2) classified MO into myositis (fibrous) ossificans progressiva, traumatic MO circumscripta, and atraumatic MO circumscripta. The latter includes the more descriptive pseudomalignant as well as idiopathic forms (2). MO is most commonly found in muscle tissue as a solitary lesion (3). Myositis ossificans can be categorized into nonhereditary and hereditary types, with the latter being a distinct entity with a separate pathophysiology and treatment approach (4). The pathophysiology of MO formation is incompletely understood. Kan et al (5) demonstrated that the cellular mechanism of heterotopic bone formation is the result of local stem cell dysregulation in response to tissue injury and subsequent inflammation. Recent studies have demonstrated that extra-skeletal bone formation may be

Correspondence to: Professor Kamil Pohlodek, Second Department of Gynecology and Obstetrics, Comenius University of Bratislava, Faculty of Medicine, Ružinovská 6, 82606 Bratislava, Slovakia

E-mail:kpohlodek@gmail.com

Key words: breast, myositis ossificans dependent on a process known as endothelial-mesenchymal transition $(4,5)$. The clinical presentation of $\mathrm{MO}$ is variable. MO has been reported to occur in all ages, including the very young (as young as 1 year of age) and in atypical locations, including the hands, feet, ribs, head, and neck (6). Patients may present atypically, especially when the history is not clear. This atypical clinical presentation, combined with nonspecific imaging findings, often raises concerns of malignancy (4-6). MO often starts as a non-specific painful soft tissue mass that could be mistaken for an infection or a soft tissue tumor. Therefore, some authors have suggested using the more descriptive term 'pseudomalignant' $\mathrm{MO}(7,8)$. We report on an unusual pseudomalignant form of myositis ossificans in the breast.

\section{Case report}

A 31-year-old Caucasian woman with no significant previous medical history was referred to the Breast Unit of the 2nd Department of OB/GYN, University Hospital of Bratislava, Slovakia, for assessment of a growing lump in her right breast. The prominent lump was in the upper, inner quadrant of the breast, near the infraclavicular region, and fixed to the chest wall. Mammography was ineffective at visualizing the lesion because of its location, however, the remaining breast parenchyma was tumor free (Fig. 1A). Breast ultrasonography revealed an oval-shaped, low-echoic tumor of unclear etiology with a pathological pattern of blood flow, as seen on PowerDoppler imaging (Fig. 1B). Infiltrating ductal carcinoma could not be excluded. Because the tumor was fixed to the chest wall, a computed tomography scan of the chest was ordered. CT showed a tumor mass with ossification signs on the upper chest wall that appeared to be continuous with the right pectoralis major muscle (Fig. 1C and D). A core biopsy was performed on the palpable mass. A malignant form of a spindle cell tumor was suspected.

The patient underwent breast surgery, with anticipated en bloc resection of the underlying parts of thoracic wall, at the Department of Thoracic Surgery, University Hospital of Bratislava, Slovakia. Surgery was performed under general anesthesia and consisted of an quadrantectomy with en bloc resection of the underlying musculature (superior medial part of the right pectoralis major muscle).

The surgically removed specimen was lobulated and measured $5.5 \times 4.5 \times 4.0 \mathrm{~cm}$ in size, containing a $4.5 \times 3.2 \times 3.0 \mathrm{~cm}$ 


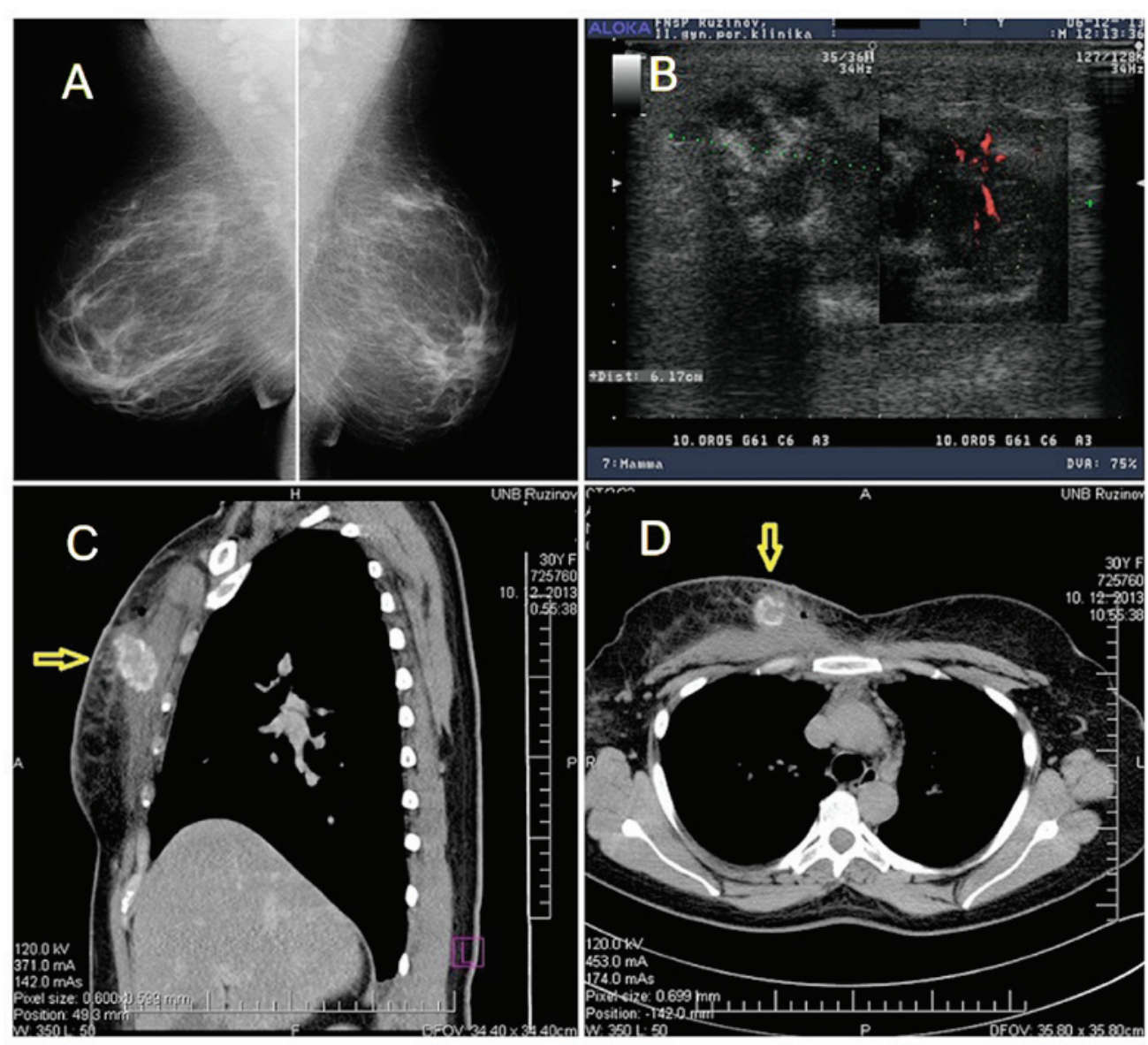

Figure 1. Breast imaging.(A) Mammography could not capture the lesion due to its location, the remaining breast parenchyma was tumor free.(B) Ultrasonography revealed an oval-shaped, low-echoic tumor of unclear aetiology with a pathological pattern of blood flow. (C) Computed tomography scan of the chest showed a tumor mass with ossification signs on the upper chest wall that appeared to be in continuity with the (D) right pectoralis major muscle.
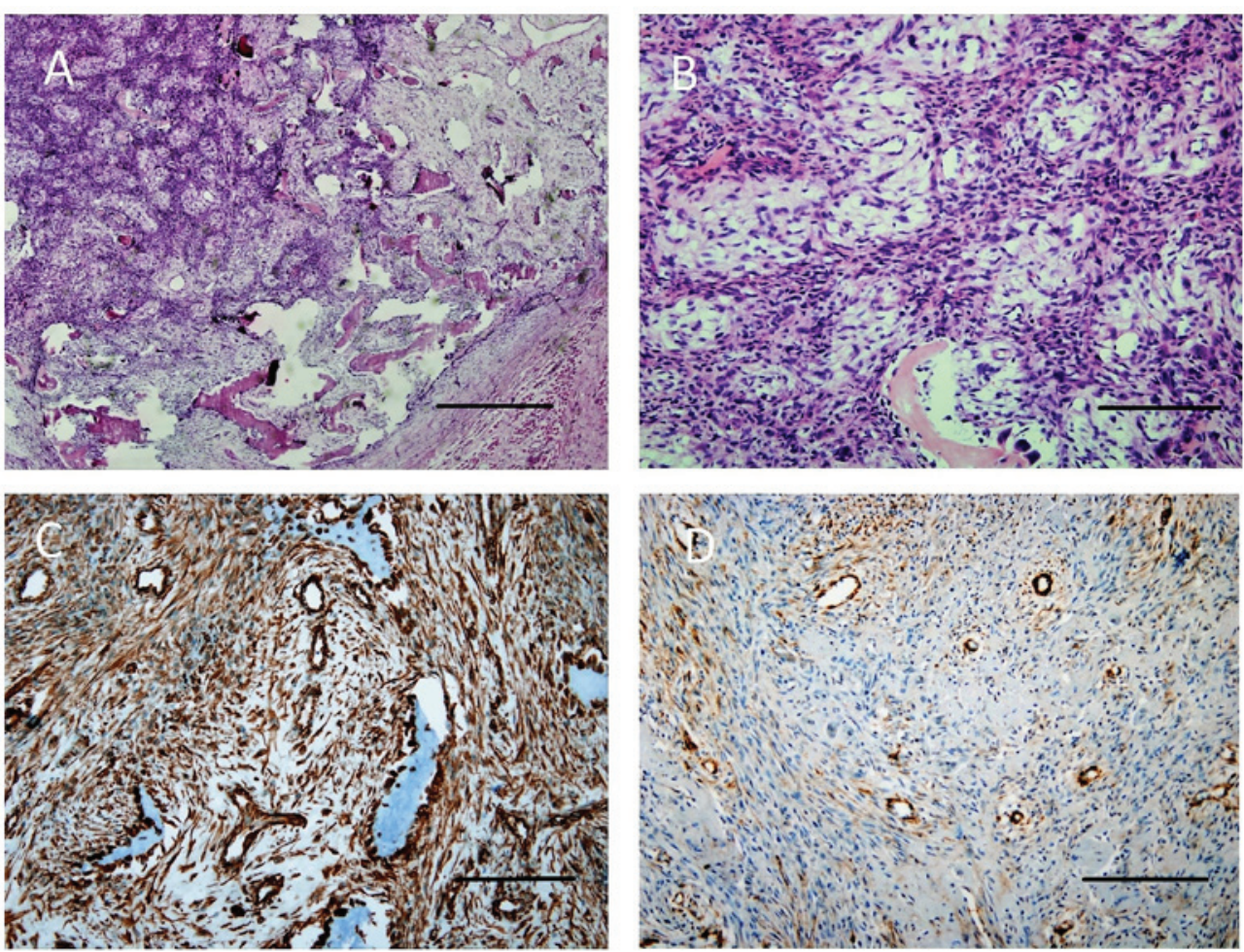

Figure 2. Histological evaluation of the tumor. (A) A nodular proliferation of spindle cells with characteristic centripethal zonation of ossification and giant osteoclasts-like cells. (B) Osteoblastic activity with marginally mature lamellar bone was present, without atypical mitoses. Immunohistochemical examination of the tumor was positive for (C) vimentin and (D) SMA protein. Scale bars, $200 \mu \mathrm{m}$. 
grossly circumscribed, capsulated firm tumor, which had infiltrated the surrounding fat and musculature. Histologic evaluation of the surgical specimens revealed nodular proliferation of spindle cells with characteristic centripetal zonation of ossification and giant osteoclasts-like cells. Osteoblastic activity with marginally mature lamellar bone was present, without atypical mitoses (Fig. 2A and B). A definitive diagnosis of a tumorous form of myositis ossificans was established from serial paraffin sectioning and immunohistochemistry (IHC). Immunostaining with anti-vimentin and anti-alpha smooth muscle actin (SMA) antibodies was positive (Fig. 2C and D), while IHC analysis with anti-cytokeratins, anti-EMA, and anti-desmin antibodies was negative. Tests for diffuse steroid receptors (estrogen and progesterone receptor) were also negative. The index of Ki67 proliferative activity was positive in $10 \%$ of cells. The patient's post-operative course was uneventful; she was discharged to home on post-operative day seven. The patient is now 48 months post-procedure and remains disease free.

\section{Discussion}

MO is essentially metaplasia of the intramuscular connective tissue resulting in extraosseous bone formation $(8,9)$. Histologically, the lesions exhibit a wide range of histologic features with different amounts of immature fibroblastic cells, osteoid, cartilage, and young or mature bone accompanied by fibrous connective tissue $(4,10,11)$. Sumiyoshi et al $(1)$, in their clinicopathologic study of 21 cases, classified MO into three types according to the predominant or most striking histologic features. Type I (6 cases) was characterized by highly cellular areas with islands of osteoid, which can occasionally be confused with extra-skeletal osteogenic sarcoma. Type II lesions (8 cases) consisted mainly of osteoid and young bone rimmed by osteoblasts, with the occasional presence of cellular areas. Type III lesions ( 7 cases) were made up, almost wholly, of mature bone and cartilage surrounded invariably by dense fibrous connective tissue. The prognosis was excellent in the 17 patients for whom follow-up information was available (1).

A biopsy is necessary to confirm the diagnosis of indeterminate lesions $(1,4,12,13)$. Due to the presence of bone formation as well as a similar epidemiology, osteosarcoma needs to be excluded. An important feature is the characteristic zonation in myositis ossificans, which is in contrast to the lace-like disorderly growth of osteoid bone formations in osteosarcomas $(5,14)$. Small biopsies can be difficult to interpret since zonation is usually not present (14).

Surgical excision is generally reserved for symptomatic MO lesions (15). However, since recurrence has been reported, excision with clear resection margins is recommended $(10,15)$. Because of the infiltration of the MO tumor into the chest wall in our patient, a thoracic surgeon (M.J.) was part of our surgical team.

Tumorous forms of MO in the breast are very rare. Salomonowitz et al (16) reported the first case in a healthy 21-year-old female who developed a rapidly growing mass in her left breast, which proved to be a non-progressive form of MO that had originated in fat tissue. Clinically, the tumor measured more than $6 \mathrm{~cm}$ in length and showed all the signs of carcinoma. In 2004, Alonso Calderón et al (17) described a 15-year-old girl with atraumatic MO circumscripta in the axillary region. A case of $\mathrm{MO}$ in the pectoralis muscle, associated with an extracapsular silicone implant rupture has also been described (18).

Brown and Carty (19) described a case of nodular fasciitis of the breast (a benign pseudosarcomatous proliferative lesion of the soft tissue) in a 65-year-old previously healthy woman who was referred to their breast clinic with a one-month history of a lump in her left breast lying against the pectoral muscle. A similar case was also recently reported by Choi et al (20). Fasciitis ossificans of the breast, a rare subtype of nodular fasciitis, was described by Sato et al (21) and $\mathrm{Su}$ et al (22). Simple excision, not radical resection, was recommended and was sufficient for a definite histological diagnosis and therapy because neither fasciitis ossificans nor nodular fasciitis generally recur and no transformations to sarcoma have been reported (20-22).

In the differential diagnosis of heterotopic bone forms in soft tissues, fibrodysplasia ossificans progressiva (FOP) comes into consideration. The disease is an ultra-rare genetic disorder (23). Classic FOP is caused by a recurrent activating mutation $(617 \mathrm{G}>\mathrm{A}$; R206H) in the ACVR1/ALK2 gene encoding activin A receptor type I/activin-like kinase 2, which is a bone morphogenetic protein (BMP) type I receptor. Atypical FOP patients also have heterozygous ACVR1 missense mutations in conserved amino acids (24). A diagnosis of FOP is made through clinical evaluation. Suspicion of FOP early in life, on the basis of malformed great toes, can lead to an early clinical diagnosis. During the first decade of life, sporadic episodes of painful soft tissue swellings occur and are commonly mistaken for tumors; confirmatory genetic testing is now available $(23,24)$.

In conclusion, $\mathrm{MO}$ in the breast region is rare. Since it is so rare, the present case study stands out as a noteworthy case with unique clinical features and histological findings.

\section{Acknowledgements}

Not applicable.

\section{Funding}

No funding was received.

\section{Availability of data and materials}

The datasets used and/or analyzed during the current study are available from the corresponding author on reasonable request.

\section{Authors' contributions}

KP performed the patient's examination, breast imaging, interventional breast procedures, breast surgery, and analyzed and interpreted the patient data regarding the disease. KP was a major contributor in writing the manuscript. MJ performed the final breast surgery. IM performed the histological examination of the core needle biopsy, surgical specimens, and analyzed and interpreted the patient data regarding the histology. FO assisted with the histological findings of the surgical specimens. 


\section{Ethics approval and consent to participate}

Written informed consent was obtained for patient participation.

\section{Consent for publication}

Written informed consent was obtained from patients for the publication of all associated data and images.

\section{Competing interests}

The authors declare that they have no competing interests.

\section{References}

1. Sumiyoshi K, Tsuneyoshi M and Enjoji M: Myositis ossificans. A clinicopathologic study of 21 cases. Acta Pathol Jpn 35: 1109$1122,1985$.

2. Noble TP: Myositis ossificans: A clinical and radiological study. Surg Gynecol Obstet 39: 795, 1924.

3. Kransdorf MJ, Meis JM and Jelinek JS: Myositis ossificans: MR appearance with radiologic-pathologic correlation. AJR Am J Roentgenol 157: 1243-1248, 1991.

4. Walczak BE, Johnson CN and Howe BM: Myositis Ossificans. J Am Acad Orthop Surg 23: 612-622, 2015.

5. Kan L and Kessler JA: Evaluation of the cellular origins of heterotopic ossification. Orthopedics 37: 329-340, 2014.

6. Ogilvie-Harris DJ and Fornasier VL: Pseudomalignant myositis ossificans: Heterotopic new-bone formation without a history of trauma. J Bone Joint Surg Am 62: 1274-1283, 1980.

7. Rööser B, Herrlin K, Rydholm A and Akerman M: Pseudomalignant myositis ossificans. Clinical, radiologic, and cytologic diagnosis in 5 cases. Acta Orthop Scand 60: 457-460, 1989.

8. Nuovo MA, Norman A, Chumas J and Ackerman LV: Myositis ossificans with atypical clinical, radiographic, or pathologic findings: A review of 23 cases. Skeletal Radiol 21: 87-101, 1992.

9. Tyler P and Saifuddin A: The imaging of myositis ossificans. Semin Musculoskelet Radiol 14: 201-216, 2010.
10. Mavrogenis AF, Soucacos PN and Papagelopoulos PJ: Heterotopic ossification revisited. Orthopedics 34: 177, 2011.

11. Micheli A, Trapani S, Brizzi I, Campanacci D, Resti M and de Martino M: Myositis ossificans circumscripta: A paediatric case and review of the literature. Eur J Pediatr 168: 523-529, 2009.

12. Wakely PE Jr, Almeida M and Frable WJ: Fine-needle aspiration biopsy cytology of myositis ossificans. Mod Pathol 7: 23-25, 1994.

13. Klapsinou E, Despoina P and Dimitra D: Cytologic findings and potential pitfalls in proliferative myositis and myositis ossificans diagnosed by fine needle aspiration cytology: Report of four cases and review of the literature. Diagn Cytopathol 40: 239-244, 2012.

14. Ng VWL: Pseudosarcomatous soft tissue lesions: A review. Proc Singap Healthc 19: 220-228, 2010.

15. Adebayo ET, Ayuba GI, Ajike SO and Fomete B: Myositis ossificans of the platysma mimicking a malignancy: A case report with review of the literature. J Korean Assoc Oral Maxillofac Surg 42: 55-59, 2016.

16. Salomonowitz E, Youssefzadeh S, Reiner A, Heilbron EA and Zollikofer CL: Nontraumatic myositis ossificans in the breast. Eur J Radiol 12: 130-131, 1991.

17. Alonso Calderón JL, Delgado Valdueza J and Deprada Vicente I: Myositis ossificans circumscripta in the axilla. An Pediatr (Barc) 60: 373-375, 2004

18. Mugea TT and Schiffman MA (eds): Aesthetic Surgery of the Breast. Springer Verlag, Berlin, Heidelberg, 2015.

19. Brown V and Carty NJ: A case of nodular fascitis of the breast and review of the literature. Breast 14: 384-387, 2005.

20. Choi HY, Kim SM, Jang M, Yun BL, Ahn HS, Park SY, Kim SW and Kang EY: Nodular fasciitis of the breast: A case and literature review. Ultraschall Med 36: 290-291, 2015.

21. Sato K, Oda Y, Ueda Y and Katsuda S: Fasciitis ossificans of the breast. Pathol Res Pract 203: 737-739, 2007.

22. Su TF and Chen A: Fasciitis ossificans of the breast. Breast J 20 429-430, 2014.

23. Pignolo RJ, Shore EM and Kaplan FS: Fibrodysplasia ossificans progressiva: Clinical and genetic aspects. Orphanet J Rare Dis 6: 80, 2011.

24. Wentworth KL, Bigay K, Chan TV, Ho JP, Morales BM, Connor J, Brooks E, Shahriar Salamat M, Sanchez HC, Wool G, et al: Clinical-pathological correlations in three patients with fibrodysplasia ossificans progressiva. Bone17: S8756-3282, 2017. 